DOI: $10.17805 / z p u .2015 .2 .24$

\title{
Милость и справедливость в комедии У. Шекспира «Мера за меру» и поэме А. С. Пушкина «Анджело»
}

\author{
Т. А. ШУСТИЛОВА
}

(МОСКОВСКИЙ ГОСУДАРСТВЕННЫЙ УНИВЕРСИТЕТ ИМ. М. В. ЛОМОНОСОВА)

Данная статья ставит своей целью выявить темы соотношения милости и справедливости в пьесе У. Шекспира «Мера за меру» и в ее переложении на русском языке поэме А. С. Пушкина «Анджело». Эта проблема до сих пор не ставилась в центр внимания российских литературоведов, хотя она многогранна и значима для творчества обоих поэтов.

Автор представляет результаты сопоставительного анализа названий, сюжета, системы персонажей двух произведений. Особое внимание уделяется спору Анджело и Изабеллы (у Пушкина - Изабелы), в котором разные аспекты милости и справедливости освещаются в их взаимосвязи. В высказываниях героев более или менее эксплицитно раскрывается представление о милости и справедливости как о равнозначительных качествах самого Бога. Далее рассматриваются высказывания о суде человеческом, в которых отражаются полярные взгляды персонажей на сущность закона и справедливости. Наконец, в завершение анализируются слова шекспировской Изабеллы и пушкинской Изабелы, в которых возникает оппозиция между «новым человеком» и «ветхим человеком», заменяющая иллюзорную оппозицию милости и справедливости.

При некоторых существенных различиях в постановке и решении проблемы милости и справедливости Пушкиным и Шекспиром проведенный анализ позволяет выявить весьма значительное сходство: в спорах героев и во всей идейной структуре обоих произведений сталкиваются не милость и справедливость как таковые, а “ветхий человек», противопоставляющий их друг другу, и «новый человек», для которого они едины и который в своих поступках являет одновременно милость и справедливость.

Ключевые слова: У. Шекспир, А. С. Пушкин, «Мера за меру», «Анджело», милость, справедливость.

\section{ВВЕАЕНИЕ}

$\mathbf{R}$ российском шекспироведении и пушкинистике многократно ставились вопросы о том, какую роль сыграло ознакомление с произведениями У. Шекспира в творческом пути А. С. Пушкина и в каких формах отразилось глубокое осмысление наследия английского драматурга русским поэтом. Неудивительно, что особое внимание литературоведов привлекает к себе в этой связи поэма «Анджело», представляющая собой переложение «проблемной» пьесы Шекспира «Мера за меру». Аля исследователя представляют интерес и сам факт обращения Пушкина именно к этой пьесе из всех доступных и известных ему произведений английского драматурга, и причина, по которой было оставлено исходное намерение поэта перевести ее на русский язык, и характер изменений, которые претерпел исходный текст комедии в ходе его творческого переложения, и особое внимание Пушкина к отдельным фрагментам этого текста, которые были воспроизведены в поэме «Анджело» с высокой степенью точности. Разные аспекты этих проблем рассматривались в работах М. П. Алексеева (Алексеев, 1965), Ю. А. Аевина (Иевин, 1968), М. Ю. Аотмана (Иотман, 1973), А. А. Аолинина (Аолинин, 2001), С. А. Черкасского (Черкасский, 2002), И. О. Шайтанова (Шайтанов, 2003), Н. В. Захарова (Захаров, 2014) и некоторых других литературоведов. Так как проблема милости и справедливости составляет смысловой центр в идейной структуре обоих произведений, она была затронута каждым из упомянутых исследователей. 
Тем не менее характер соотношения этих двух категорий в творчестве обоих поэтов остается, на наш взгляд, недостаточно исследованным и, учитывая значимость этой проблемы для обоих поэтов, требует нашего пристального внимания.

Цель данной статьи - обозначить спектр наиболее существенных проблем, ассоциаций и представлений, которые актуализируются в своей совокупности в связи с более или менее явным противопоставлением милости и справедливости в пьесе Шекспира «Мера за меру» и в поэме Пушкина «Анджело». В ней изложены выводы, сделанные на основе сопоставительного анализа названий, сюжета, системы персонажей и, главное, нескольких реплик героев обоих произведений.

\title{
РАЗНЫЕ НАЗВАНИЯ - РАЗНЫЕ АКЦЕНТЫ
}

В 1833 г. Пушкин принимается за перевод пьесы Шекспира «Мера за меру, однако позднее решает переделать ее в поэму. Сущность преобразований, которые происходят при этом с произведением английского драматурга, отразилась в первую очередь в выборе отличного от шекспировской пьесы названия - «Анджело».

Название «Мера за меру» напрямую отсылает к христианским представлениям о справедливости и милости в их взаимосвязи и исторической динамике - от ветхозаветного понимания к новозаветному (Захаров, 2014: 244). Именно эти представления являются смысловым центром пьесы. Многообразие ситуаций, в которых оказываются ее герои, позволяет Шекспиру осветить различные аспекты заявленной в названии темы и представить ее в разных ракурсах. Не случайно М. К. Брэдбрук называла комедию «Мера за меру» «самым теоретическим произведением Шекспира» (Bradbrook, 1941: 385).

Если английский драматург в первую очередь стремится исследовать в своем произведении суть христианских заповедей, то Пушкин, вынося в заглавие своей поэмы имя одного из шекспировских героев, фокусирует внимание читателя на личности этого героя (столь поразившего русского поэта глубиной своего характера $)^{1}$ и на драме, разворачивающейся в его душе.

Итак, различия в художественном замысле двух произведений весьма велики. Тем интереснее обратить внимание на сходства между некоторыми фрагментами двух текстов.

Как неоднократно отмечалось отечественными литературоведами, отдельные реплики пушкинских героев представляют собой довольно точный перевод шекспировской пьесы (Аолинин, 2001: 47). К числу таких фрагментов относится диалог между Изабеллой и Анджело, в котором юная послушница умоляет сурового наместника помиловать ее брата за совершенное им прелюбодеяние. Сосредоточим внимание на двух репликах героев Шекспира и на аналогичном фрагменте поэмы Пушкина. Их сопоставительный анализ позволит нам отметить существенные сходства и некоторые различия в том, как освещают проблему милости и справедливости английский драматург и русский поэт.

\section{Анджело}

Ваш брат законом осужден, не мной, И слов не тратьте зря.

\author{
Изабелла \\ Увы, увы! \\ Ведь были души все осуждены,
}


И Он, Кто мог бы всех нас осудить,

Нашел спасение. Что было б с вами,

Когда бы Он, судья всевышний, стал

Судить вас строго? Вспомните об этом,

И милости дыхание повеет

Из ваших уст, и станете тогда

Вы новым человеком.

$<$...> «Подумай, - говорила, -

«Мера за меру» $(\mathrm{II}, 2)^{2}$

Подумай, если тот, чья праведная сила

Прощает и целит, судил бы грешных нас

Без милосердия; скажи: что было б с нами?

Подумай - и любви услышишь в сердце глас,

И милость нежная твоими дхнет устами,

И новый человек ты будешь».

\section{XII}

Oн $\mathrm{B}$ ombem:

«Поди; твои мольбы пустая слов утрата.

Не я, закон казнит. Спасти нельзя мне брата, И завтра он умрет».

«Анджело» (Часть первая, XI-XII) ${ }^{3}$

В обоих фрагментах мольба о помиловании перерастает на наших глазах в спор о соотношении милости и справедливости, Божьего суда и человеческого, воли правителя и закона. Хотя Пушкин в целом воспроизводит текст английского драматурга достаточно точно, обратим внимание на некоторые существенные различия.

\section{ПРЕАСТАВАЕНИЕ О БОЖИЕМ СУАЕ}

Аля начала сопоставим те слова, в которых выражается здесь представление о соотношении милости и справедливости как двух равнозначимых характеристик Божьего суда над человеком. Аопустим небольшой анахронизм и начнем с Пушкина. В первых четырех строках процитированного выше фрагмента праведность, справедливость Бога и его милость к человеку представлены в их взаимосвязи как некие «постоянные свойства» Бога; этому способствует использование настоящего времени.

Теперь обратимся к соответствующим стихам в тексте Шекспира. В отличие от пушкинского текста в них используется прошедшее время: призыв к правителю явить милость звучит на фоне внезапно открывающейся исторической перспективы. Значение этого предложения можно раскрыть примерно так: весь человеческий род был осужден, но Бог, вместо того чтобы покарать человека и привести в исполнение свой справедливый приговор, находит средство спасти человека от наказания (“found out the remedy"), т. е. являет милость. Причем слово 'remedy' используется с определенным артиклем, и это указывает на то, что героиня намекает на некое конкретное событие. Что же имеется в виду? Шекспировской аудитории этот намек был понятен: привычка связывать единение милости и справедливости в Божьем суде с определенным событием человеческой истории имела глубокие корни в английской культуре начала XVII в.

В средневековой Европе был чрезвычайно популярен сюжет, в основу которого был положен стих из 84-го псалма: 
Милость и истина сретятся, правда и мир облобызаются (Пс. 84: 11).

Это сюжет о четырех дочерях Бога - Мире, Правде, Справедливости и Милости, которые спорят о судьбе Человека (Человечества). Правда и Справедливость настаивают на необходимости наказания, а Милость и Мир - на необходимости спасения. Среди английских поэтических и драматических вариаций этого сюжета есть и такие, в которых примирение и совместное торжество четырех сестер связывается с искупительной жертвой Христа (Traver, 1907: 126-135). Беря на себя грех мира и претерпевая за него страдание, Бог одновременно являет справедливость (за человеческий грех проливается человеческая кровь) и милость. Отголоски именно этой вариации сюжета мы находим в аллегорической поэме современника Шекспира - Ажайлса Флетчера - «Победа Христа и торжество на небесах и земле над смертью и после нее» (Christ's Victory and Triumph, in Heaven, in Earth, over and after Death, 1610). Поэма, прославляющая искупительную жертву Христа, открывается спором Милости и Справедливости, а все ее последующее действие становится разрешением этого спора.

Таким образом, Шекспиру было достаточно одного намека, одного парафраза, для того чтобы за спором его героев зрители различили голоса хорошо знакомых аллегорических персонажей и чтобы в их памяти сразу же всплыла целая религиозно-философская концепция. Шекспир опирался на определенную традицию, аналога которой не было в русской культуре. И потому Пушкин, ориентируясь на русского читателя, даже если сумел осознать глубину этой фразы Шекспира, по-видимому, не стал пытаться отразить в полной мере сокрытые в ней смыслы ${ }^{4}$.

\section{ПРОБАЕМА СУАА ЧЕАОВЕЧЕСКОГО}

Как у Шекспира, так и у Пушкина героиня призывает Анджело подражать Богу именно в милости, а не в роли судьи. Согласно евангельским заповедям и притчам, к которым многократно отсылают Шекспир и Пушкин в тексте пьесы и поэмы, именно милость должны являть люди по отношению друг к другу, так как не имеют права судить других, особенно за то, в чем провинились сами.

Однако ситуация осложняется тем, что отношения между господином и подданными являются для современников Шекспира в то же время проекцией отношений между Богом и человеком. Таким образом, перед человеком, наделенным властью, возникает проблема: как человек, он не должен осуждать, так как и сам грешен; но как наместник Божий, правитель должен вершить на земле некое подобие Божьего суда. Как решает эту проблему Анджело?

В обоих произведениях Анджело как бы дистанцируется от закона, который он намеревается привести в исполнение: «Ваш брат законом осужден - не мной» (Шекспир) / «Не я, закон казнит» (Пушкин), - говорит он Изабелле.

К совершенно иному выводу приходит шекспировский Герцог. Итог его размышлений выражается в монологе, который выделяется в тексте пьесы даже ритмически: пятистопный ямб сменяется четырехстопным, более того, в нем появляется рифма, придающая словам героя особую звучность, а его мыслям - формульность и завершенность:

Кому свой меч вручает Бог,

Быть должен так же свят, как строг:

Собою всем пример являть,

В чем чистота и благодать, 


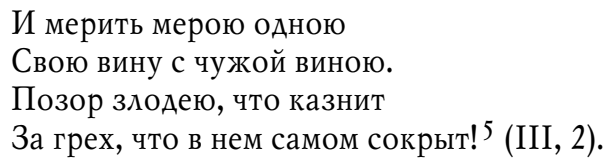

Требование милости и справедливости, предъявляемое к правителю, предполагает для Герцога и требование праведности, даже святости.

Показательно, что в поэме Пушкина нет аналога этому монологу: политический аспект справедливости и милости выносится русским поэтом на периферию идейной структуры поэмы, как и сам образ Аука. Старый Аук едва ли может восприниматься как антипод Анджело. У Шекспира, напротив, Герцог и его суровый наместник последовательно противопоставляются друг другу как два правителя, руководствующиеся разными чувствами к своим подданным, разными представлениями о справедливости и законе. В понимании Анджело закон стоит над волей земного владыки. В понимании Герцога, напротив, живая личность, а не безжизненный принцип должна вершить на земле суа.

В связи с этим стоит упомянуть об образе разбойника Бернардина, который отсутствует у Пушкина. Вина этого героя доказана, но Герцог милует его лишь на том основании, что тот не готов к смерти, заботясь не о формальном соблюдении порядка, а о спасении души своего подданного. Тем разительнее контраст с Анджело, который оставляет без внимания слова Изабеллы о том, что приговоренный им к казни Клавдио не готов к смерти. У обоих поэтов Анджело отвечает на мольбы Изабеллы, что до сего времени закон спал, но теперь пришло время ему проснуться. У Пушкина это звучит так:

Закон не умирал, но был лишь в усыпленье,

Теперь проснулся он ${ }^{6}$.

Образ спавшего, но пробуждающегося закона, заимствованный русским поэтом у Шекспира, в то же время заставляет вспомнить собственный образ Пушкина из его раннего стихотворения - оды «Вольность» (1817). Теперь, спустя семнадцать лет, автор поэмы «Анджело» дистанцируется от автора оды «Вольность», вкладывая похожие слова в уста героя, дискредитирующего своими поступками мировоззрение, в котором главенствующее место принадлежит закону и в котором справедливость исключает милость.

\section{«НОВЫЙ» И «ВЕТХИЙ ЧЕАОВЕК}

Наконец, обратим внимание еще на один момент в реплике Изабеллы, умоляющей Анджело о милости: идея милости связывается в ее словах с образом «нового человека».

Пушкин вносит некоторые изменения в слова героини, еще больше усиливая намеченную Шекспиром связь. В христианстве «новым человеком» называется тот, кто благодаря действию божественной благодати делает то, что должно и справедливо, по любви и по доброй воле и «обновляется в познании по образу Создавшего его...» (Кол. 3:10). В Послании к Ефесянам, где апостол Павел также обращается к этому образу, христиане, «облекшиеся в нового человека», противопоставлены людям, которые «помрачены в разуме» и «отчуждены от жизни Божией, по причине их невежества и ожесточения сердца их» (Еф. 4:18). Пушкин дополняет фразу Шекспира словом «любовь »: «Подумай - и любви услышишь в сердце глас». Таким образом он еще более отчетливо выражает в словах Изабелы представление о действии божественной 
благодати, способной преобразить человеческое сердце, т. е. саму человеческую природу с ее желаниями и стремлениями.

Сглаживая значимую для Шекспира оппозицию между Анджело и Герцогом, Пушкин, пожалуй, еще больше, чем Шекспир, заостряет внимание на противостоянии Анджело и Изабелы. При этом, как уже отмечалось в некоторых работах, Пушкин придает образу и словам своей героини бо́льшую мягкость, душевную теплоту, чем английский драматург, сокращает некоторые теоретические рассуждения шекспировской героини. Таким образом, русский поэт дает почувствовать читателю, что Изабела поступает милостиво и справедливо не потому, что руководствуется некими идеями, а потому, что «слышит глас любви в сердце», в отличие от сурового наместника, который, выражаясь словами апостола Павла, «помрачен в разуме» и «отчужден от жизни Божией, по причине своего невежества и ожесточения сердца своего».

Итак, если Шекспир делает христианскую заповедь о милости и справедливости центральной темой свой пьесы, раскрытию которой служит сюжет, то Пушкин сосредоточивает внимание преимущественно на личности героя, в понимании которого милость и справедливость - две вещи несовместные, и на внутренней драме, к которой приводит человека такая система убеждений. При этом Пушкин опускает некоторые сюжетные линии шекспировского произведения, позволяющие раскрыть заявленную в названии тему в дополнительных ракурсах. Однако в обоих произведениях противопоставление милости и справедливости в суде Божьем и человеческом осмысляется как ложная оппозиция.

\section{ЗАКАЮЧЕНИЕ}

В произведениях обоих поэтов представления о соотношении милости и справедливости в Божьем суде и суде человеческом раскрываются в их тесной взаимосвязи. Противопоставление милости и справедливости в словах Анджело осмысляется при этом как ложная оппозиция, которая снимается по мере развития сюжета благодаря словам и, главное, образу таких цельных героев, как Изабелла и шекспировский Герцог, для которых две эти категории немыслимы в отрыве друг от друга. В спорах героев и во всей идейной структуре обоих произведений сталкиваются не милость и справедливость, а «ветхий человек», противопоставляющий их друг Аругу, и «новый человек», руководствующийся в первую очередь тем законом, который запечатлен у него «в сердце, по духу, а не по букве» (Рим. 2:29), и потому поступающий одновременно милостиво и справедливо.

\section{ПРИМЕЧАНИЯ}

1 В своих заметках, объединенных названием “Table-talk” (1830-е годы), Пушкин очень высоко отзывается о художественных достоинствах образа Анджело: «Анжело лицемер - потому что его гласные действия противуречат тайным страстям! А какая глубина в этом характеpe!» (Пушкин, 1962: 210).

2 В процитированном тексте совмещены переводы Т. $\Lambda$. Щепкиной-Куперник (три последних стиха) и М. А. Зенкевича, что позволяет более полно отразить смысл оригинала (соответственно см.: Шекспир, 1960: 195; Шекспир, 2014: 36).

${ }^{3}$ Цит. по: Пушкин, 1960: 267.

${ }^{4}$ Однако интересно, что размышления о жертве Христа и о власти Божией и человеческой возникают в их тесной взаимосвязи в другом, более позднем произведении Пушкина - в стихотворении 1836 г. «Мирская власть». В этом проявляется удивительная общность мировоззрений двух поэтов.

5 Перевод Т. А. Щепкиной-Куперник. Цит. по: Шекспир, 1960: 230-231.

${ }^{6}$ Цит. по: Пушкин, 1960: 267. 


\section{СПИСОК АИТЕРАТУРЫ}

Алексеев, М. П. (1965) А. С. Пушкин // Шекспир и русская культура. М. ; $\Lambda$. : Наука. 823 с. C. $162-200$.

Аолинин, А. А. (2001) Пушкин и Англия // Всемирное слово. № 14. С. 44-51.

Захаров, Н. В. (2014) Шекспиризм в творчестве А. С. Пушкина // Знание. Понимание. Умение. № 2. С. 235-249.

Иевин, Ю.А. (1968) Об источниках поэмы Пушкина «Анджело»// Известия Академии наук СССР. Сер. литературы и языка. Т. XXVII. Вып. 3. М. : Наука. С. 255-258.

Иотман, Ю. М. (1973) Идейная структура поэмы Пушкина «Анджело» // Ученые записки АГПИ. Пушкинский сборник. Псков : ИзА-во АГПИ. С. 3-23.

Пушкин, А. С. (1960) Анджело // Пушкин, А. С. Полн. собр. соч. : в 10 т. М. : Гос. изд-во худ. лит. Т. 3.543 с. С. 262-283.

Пушкин, А. С. (1962) Table-talk // Пушкин, А. С. Полн. собр. соч. : в 10 т. М. : Гос. изА-во худ. лит. Т. 7.463 с. С. 206-222.

Черкасский, С. А. (2002) Ава гения - один сюжет (драма Шекспира «Мера за меру» и поэма Пушкина «Анджело») // Пушкин и его современники : сб. науч. тр. Вып. 3 (42). СПб. : Академический проект. 445 с. С. 80-104.

Шайтанов, И. О. (2003) Аве «неудачи»: «Мера за меру» и «Анджело»: Пушкин и Шекспир // Вопросы литературы. № 1. С. 123-148.

Шекспир, В. (1960) Мера за меру / пер. Т. А. Щепкиной-Куперник // Шекспир, В. Полн. собр. соч. : в 8 т. / под общ. ред. А. А. Смирнова, А. А. Аникста. М. : Искусство. Т. 6. 687 с. С. 159-279.

Шекспир, У. (2014) Мера за меру / пер. с англ. М. Зенкевича // Шекспир, У. Мера за меру. Венецианский купец : комедии. СПб. : Азбука ; Азбука-Аттикус. 224 с. С. 5-118.

Bradbrook, M. C. (1941) Authority, truth, and justice in "Measure for Measure" // The Review of English Studies. October. Vol. XVII. No. 68. P. 385-399.

Traver, H. (1907) The four daughters of God: A study of the versions of this allegory with especial reference to those in Latin, French, and English. Philadelphia : J. C. Winston. 171 p.

Дата поступления: 5.02.2015 2.

\section{MERCY AND JUSTICE IN SHAKESPEARE'S "MEASURE FOR MEASURE" \\ AND A. S. PUSHKIN'S “ANGELO” \\ T. A. SHUSTILOVA \\ (LOMONOSOV MOSCOW STATE UNIVERSITY)}

The article aims to analyze the relationship between the categories of mercy and justice in Shakespeare's "Measure for Measure" and Pushkin's "Angelo". This problem has not yet received a dedicated piece of research, while it truly deserves critics' full attention, considering its multifaceted nature and the significance attributed to it by both poets.

The author presents the outcomes of a comparative analysis of the titles, plots, systems of characters of the two works. Special attention has been paid to the argument between Angelo and Isabella ('Isabela' - in Pushkin's poem) in which different aspects of mercy and justice are shown as intrinsically related to each other. In the first place, the phrases of the characters reflect more or less explicitly the perception of mercy and justice as two equally important qualities of God himself. Then the phrases about earthly justice are shown as comprising opposite attitudes to law. The last section analyzes the words of Shakespeare's and Pushkin's female protagonist in which she implicitly sets the Biblical notions of 'old humanity' and 'new humanity' against each other, thus rejecting the opposition of mercy and justice as an irrelevant one.

To sum up, although there are certain significant differences in the way the two poets deal with the problem of mercy and justice, the analysis has revealed an essential similarity. It is not mercy and justice as such that come into collision in the arguments of the characters and the inner structure of both works, but the 'old humanity' which erroneously considers them incompatible, and the "new humanity' which does not separate the one from the other and perceives them as two sides of one whole.

Keywords: Shakespeare, Pushkin, "Measure for Measure”, “Angelo”, mercy, justice. 


\section{REFERENCES}

Alekseev, M. P. (1965) A. S. Pushkin [A.S. Pushkin]. In: Shekspir i russkaia kul' tura [Shakespeare and Russian culture]. Moscow ; Leningrad, Nauka Publ. Pp. 162-200. (In Russ.).

Dolinin, A. A. (2001) Pushkin i Angliia [Pushkin and England]. Vsemirnoe Slovo, no. 14, pp. 44-51. (In Russ.).

Zakharov, N. V. (2014) Shekspirizm v tvorchestve A. S. Pushkina [Shakespearianism in Pushkin's creative works]. Znanie. Ponimanie. Umenie, no. 2, pp. 235-249. (In Russ.).

Levin, Yu. D. (1968) Ob istochnikakh poemy Pushkina «Andzhelo» [On the sources of Pushkin's "Angelo"]. Izvestiia Akademii nauk SSSR. Seriia literatury $i$ iazyka, vol. XXVII, issue 3, pp. 255-258. (In Russ.).

Lotman, Yu. M. (1973) Ideinaia struktura poemy Pushkina «Andzhelo» [The inner structure of Pushkin's poem "Angelo"]. In: Uchenye zapiski LGPI. Pusbkinskii sbornik. Pskov, Leningrad State Pedagogical Institute Publ. Pp. 3-23. (In Russ.).

Pushkin, A. S. (1960) Andzhelo [Angelo]. In: Pushkin, A. S. Polnoe sobranie sochinenii [Complete works] : in 10 vols. Moscow, State Publishing House of Fiction. Vol. 3. 543 p. Pp. 262-283. (In Russ.).

Pushkin, A. S. (1962) Table-talk. In: Pushkin, A. S. Polnoe sobranie sochinenii [Complete works] : in 10 vols. Moscow, State Publishing House of Fiction. Vol. 7. 463 p. Pp. 206-222. (In Russ.).

Cherkasskii, S. D. (2002) Dva geniia - odin siuzhet (Drama Shekspira «Mera za meru» i poema Pushkina «Andzhelo») [Two Geniuses - one plot (Shakespeare's play "Measure for Measure" and Pushkin's poem "Angelo")]. In: Pushkin i ego sovremenniki [Pushkin and his contemporaries] : collection of research articles. No. 3 (42). St. Petersburg, Akademicheskii proekt Publ. 445 p. Pp. 80-104. (In Russ.).

Shaitanov, I. O. (2003) Dve «neudachi»: «Mera za meru» i «Andzhelo»: Pushkin i Shekspir [Two Failures: "Measure for Measure" and "Angelo": Pushkin and Shakespeare]. Voprosy literatury, no. 1, pp. 123-148. (In Russ.).

Shakespeare, W. (1960) Mera za meru [Measure for Measure]/ transl. by T. L. Shchepkina-Kupernik. In: Shakespeare, W. Polnoe sobranie socbinenii [Complete works] : in 8 vols. / ed. by A. A. Smirnov, A. A. Anikst. Moscow, Iskusstvo Publ. Vol. 6. 687 p. Pp. 159-279. (In Russ.).

Shakespeare, W. (2014) Mera za meru [Measure for Measure]/ transl. from English by M. Zenkevich. In: Shakespeare, W. Mera za meru. Venetsianskii kupets: komedii [Measure for Measure. The Merchant of Venice : Comedies]. St. Petersburg, Azbuka Publ. ; Azbuka-Attikus Publ. 224 p. Pp. 5-118. (In Russ.).

Bradbrook, M. C. (1941) Authority, truth, and justice in "Measure for Measure". The Review of English Studies, October, vol. XVII, no. 68, pp. 385-399.

Traver, H. (1907) The four daughters of God: A study of the versions of this allegory with especial reference to those in Latin, French and English. Philadelphia, J. C. Winston. 171 p.

Submission date: 5.02 .2015 .

Шустилова Татьяна Антоновна - аспирант кафедры истории зарубежной литературы филологического факультета Московского государственного университета им. М. В. Аомоносова. Адрес: 119991, Россия, г. Москва, Аенинские горы, ГСП-1, 1-й корпус, филологический факультет. Тел.: +7 (495) 939-27-84. E-mail: mid_morning@mail.ru. Научный руководитель - А-р филол. наук, проф. А. Н. Горбунов.

Shustilova Tatiana Antonovna, Postgraduate Student, Department of the History of Foreign Literatures, Faculty of Philology, Lomonosov Moscow State University. Postal address: Faculty of Philology, 1st building, GSP-1, 119991 Moscow, Russian Federation. Tel.: +7 (495) 939-27-84. E-mail: mid_morning@mail.ru. Research adviser: A. N. Gorbunov, Doctor of Philology, Professor. 